\title{
Retracted: Nutritional and Biochemical Parameters Among Multiple Sclerosis Patients: A Case-Control Study
}

\author{
Asjad Salman ${ }^{1}$, Sabeeh Islam ${ }^{2}$, Muhammad Awais Saleh ${ }^{3}$, Khurram Khaliq Bhinder ${ }^{4}$, Zainab Malik ${ }^{4}$, Iqra \\ Tahir ${ }^{5}$, Muhammad A. Naveed 6,7 \\ 1. Internal Medicine, Punjab Rangers Teaching Hospital, Lahore, PAK 2. Internal Medicine, St. Vincent Health Center, \\ Buffalo, USA 3. Internal Medicine, Government Khawaja Muhammad Safdar Medical College and Allied Institutions, \\ Sialkot, PAK 4. Radiology, Shifa International Hospital Islamabad, Islamabad, PAK 5. Internal Medicine, Lahore General \\ Hospital, Lahore, PAK 6. Cardiology, Allama Iqbal Memorial Teaching Hospital, Sialkot, PAK 7. Cardiology, Government \\ Khawaja Muhammad Safdar Medical College and Allied Institutions, Sialkot, PAK
}

Corresponding author: Muhammad Awais Saleh, awaissaleh@gmail.com

Corresponding author: Muhammad Awais Saleh

1. Internal Medicine, Punjab Rangers Teaching Hospital, Lahore, PAK 2. Internal Medicine, St. Vincent Health Center, Buffalo, USA 3. Internal Medicine, Government Khawaja Muhammad Safdar Medical College and Allied Institutions, Sialkot, PAK 4. Radiology, Shifa International Hospital Islamabad, Islamabad, PAK 5. Internal Medicine, Lahore General Hospital, Lahore, PAK 6. Cardiology, Allama lqbal Memorial Teaching Hospital, Sialkot, PAK 7. Cardiology, Government Khawaja Muhammad Safdar Medical College and Allied Institutions, Sialkot, PAK

How to cite this retraction

Salman A, Islam S, Saleh M, et al. (May 27, 2021) Retraction: Nutritional and Biochemical Parameters Among Multiple Sclerosis Patients: A Case-Control Study. Cureus 13(5): r31. doi:10.7759/cureus.r31

\section{Retraction Notice}

This article has been retracted due to allegations that the study data was plagiarized from an alreadypublished article in Neurology India: https://www.neurologyindia.com/article.asp?issn=00283886; ;ear $=2020$; volume $=68$;issue $=4$; spage $=867$; epage $=874 ;$ aulast $=$ Akbay

After conducting our own investigation, Cureus has made the decision to formally retract this article.

A key condition of article submission is that authors must explicitly declare that their work is original and has not appeared in publication elsewhere. Re-use of any data must be appropriately cited. As such this article represents a severe abuse of the scientific publishing system. The Cureus Journal of Medical Science takes a very strong view on this matter and we apologize that this was not detected during the submission process. 